\title{
Multimodal Longitudinal Imaging of Focal Status Epilepticus
}

\author{
Colin P. Doherty, Andrew J. Cole, P. Ellen Grant, Alan Fischman, \\ Elizabeth Dooling, Daniel B. Hoch, Tessa Hedley White, G. Rees Cosgrove
}

\begin{abstract}
Background: Little is understood about the evolution of structural and functional brain changes during the course of uncontrolled focal status epilepticus in humans. Methods: We serially evaluated and treated a nine-year-old girl with refractory focal status epilepticus. Long-term EEG monitoring, MRI, MRA, SPECT, intraoperative visualization of affected cortex, and neuropathological examination of a biopsy specimen were conducted over a three year time span. Imaging changes were correlated with simultaneous treatment and EEG findings. Results: The EEG monitoring showed almost continuous spike discharges emanating initially from the right frontocentral area. These EEG abnormalities were intermittently suppressed by treatment with anesthetics. Over time, additional brain areas developed epileptiform EEG abnormalities. Serial MRI studies demonstrated an evolution of changes from normal, through increased regional T2 signal to generalized atrophy. An MRAdemonstrated dilatation of the middle cerebral artery stem on the right compared to the left with a broad distribution of flow-related enhancement. An ${ }^{18}$ FDG-PET scan showed a dramatically abnormal metabolic profile in the same right frontocentral areas, which modulated in response to treatment during the course of the illness. A right frontotemporal craniotomy revealed a markedly hyperemic cortical focus including vascular shunting. A sample of resected cortex showed severe gliosis and neuronal death. Conclusions: The co-registration of structural and functional imaging and its correlation with operative and pathological findings in this case illustrates the relentless progression of regional and generalized abnormalities in intractable focal status epilepticus that were only transiently modified by exhaustive therapeutic interventions. Increased flow through large vessels appeared to be shunted and did not translate into increased microvascular perfusion.
\end{abstract}

RÉSUMÉ: Imagerie longitudinale multimodale du status épilepticus focal. Introduction: La compréhension de l'évolution des changements structuraux et fonctionnels pendant le status épilepticus focal dans le cerveau humain est très limitée. Méthodes: Nous avons effectué une évaluation sériée chez une fillette de neuf ans que nous suivons pour un status épilepticus focal réfractaire au traitement. Le monitorage ÉEG à long terme, l'IRM, l'ARM, la TEMP, la visualisation peropératoire du cortex atteint et l'examen neuropathologique d'un spécimen anatomopathologique ont été réalisés sur une période de trois ans. Les changements à l'imagerie étaient corrélés au traitement et aux observations à l'ÉEG. Résultats: Le monitorage ÉEG a montré des décharges de pointes émanant initialement de la zone fronto-centrale droite. Ces anomalies électroencéphalographiques étaient supprimées de façon intermittente par les anesthésiques. Avec le temps, des anomalies épileptiformes à l'ÉEG sont apparues dans d'autres régions du cerveau. L'IRM en série a montré une évolution des changements dans les zones initialement normales, soit d'un signal régional T2 augmenté à une atrophie généralisée. L'ARM a montré une dilatation du tronc de l'artère cérébrale moyenne du côté droit par rapport au gauche, avec une distribution large du rehaussement relié au flot. Un PETscan au 18FDG a montré un profil métabolique très anormal dans cette zone fronto-centrale droite qui était modulé par le traitement pendant l'évolution de la maladie. À la craniotomie fronto-temporale droite, on a observé un foyer cortical très hyperhémique avec dérivation vasculaire. Une biopsie du cortex a montré une gliose sévère avec mort neuronale. Conclusions: L'imagerie structurelle et fonctionnelle utilisée conjointement, en corrélation avec les observations chirurgicales et anatomopathologiques, illustrent la progression implacable des anomalies régionales. Elles se sont éventuellement généralisées chez cette patiente présentant un status épilepticus réfractaire au traitement, et n'étaient modifiées que temporairement par des interventions thérapeutiques exhaustives. L'accroissement du flot sanguin dans les gros vaisseaux semblait dévié et n'entraînait pas d'augmentation de la perfusion microvasculaire.

Can. J. Neurol. Sci. 2004; 31: 276-281

Status epilepticus (SE), a condition characterized by persistent seizures presents a difficult clinical problem. While it is clear that major motor seizures can lead to permanent pathological damage and altered physiological function, the changes accompanying more focal discharges are less clear. ${ }^{1}$ Epilepsia partialis continua is a form of SE characterized by continuous, well-localized, clonic, focal motor myotonias. Epilepsia partialis continua is notoriously refractory to anti-
From the Epilepsy Service, Neurology Service, (CPD, AJC, DBH); Department of Neuroradiology, (PEG); Nuclear Medicine Unit, Department of Radiology, (AF); Epilepsy Surgery Unit, Neurosurgical Service, (GRC); Pediatric Neurology, Department of Neurology, (ED); Department of Neuropathology, (THW)

Massachusetts General Hospital and Harvard Medical School, Boston, USA. ReCEIVED April 28, 2003. ACCEPTED InFINALFORM NOVEMBER 17, 2003. Reprint requests to: Andrew J. Cole, MGH Epilepsy Service, VBK-830, Massachusetts General Hospital, Fruit Street, Boston, Massachusetts 02114 USA 


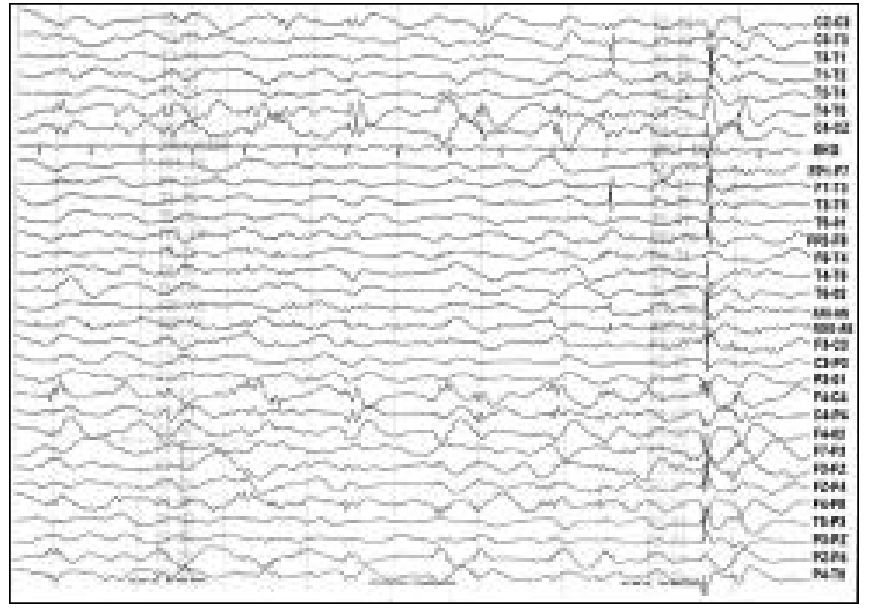

Figure 1: 22 Lead EEG, day 13 of status epilepticus showing generalized background slowing and continuous $1 \mathrm{~Hz}$ sharp discharges in the right central regions (C4) which were only occasionally associated with clinical seizure activity in the left arm and face. hospital. On arrival she was unconscious but breathing spontaneously on a respirator. Clinically obvious focal seizure activity affecting the left side was observed in episodes lasting 15 minutes every one to two hours (Figure 1). The EEG examination showed continuous sharp discharges occurring at $1 \mathrm{~Hz}$ arising from the right central region. An extensive biochemical, metabolic and infectious work-up failed to reveal a cause. Cerebrospinal fluid examination on two occasions showed no cells, total protein of 11 and $16 \mathrm{mg} / \mathrm{dl}$, appropriate glucose levels, minimally elevated lactate (2.6 and $3.4 \mathrm{mmol} / \mathrm{l}$, upper range of normal 2.2) and a normal electrophoresis pattern without oligoclonal bands. Bacterial, fungal and viral studies were negative. GluR3 antibodies were not detected in serum or CSF. Magnetic resonance imaging of the brain showed increased T2 signal in right hemisphere involving cortex, adjacent white matter and thalamus (Figure 2A). These changes were concordant with widespread metabolic abnormalities on ${ }^{18}$ fluro-2deoxy-glucose positron emission tomography $\left({ }^{18}\right.$ FDG-PET)(Figure $2 B$ ). A magnetic resonance angiogram (MRA) showed massive dilation of the right middle cerebral artery with increased flow related enhancement in the middle cerebral artery territory (Figure 2C). Single photon emitted computed tomography (SPECT) scan after injection with ${ }^{99} \mathrm{Tc}-\mathrm{HMPAO}$

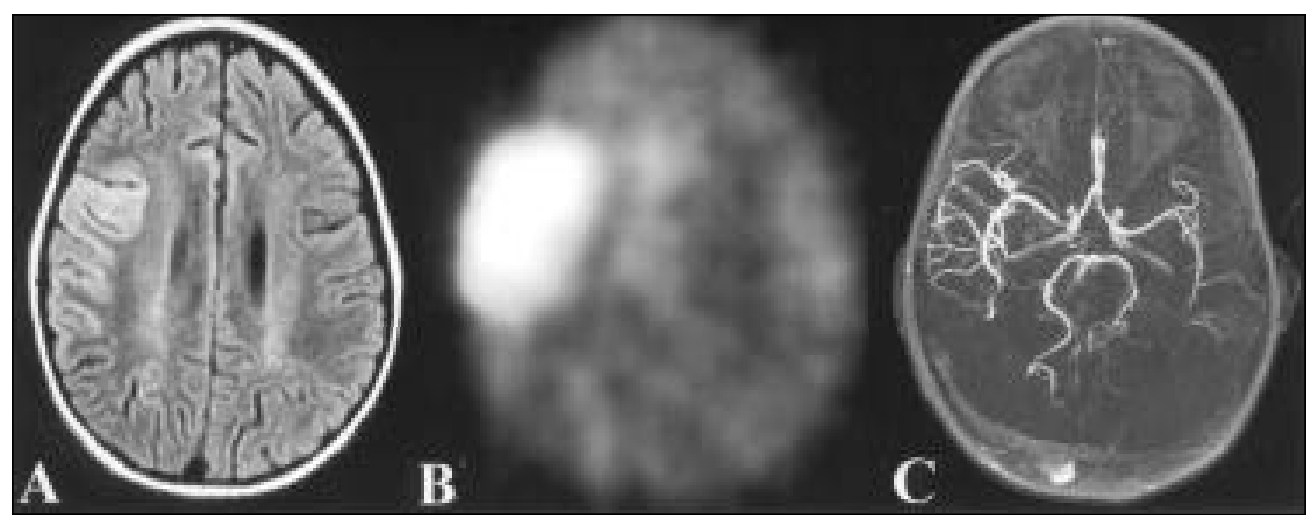

Figure 2: Composite figure of imaging on day 14 of status epilepticus. Axial fluid attenuated inversion recovery (FLAIR) image showing increased signal in cortical and white matter regions in right frontotemporal areas (2A). ${ }^{18} F D G-P E T$ scan showing increased uptake of radio-labeled glucose in the same right frontotemporal region (2B). An MR angiogram showing dilatation of the right middle cerebral artery branches presumably reflecting increased blood flow to the active cortex $(2 C)$.

epileptic medical therapy but may respond better to subpial transection ${ }^{2}$ or resection. Epilepsia partialis continua is often a sign of a serious progressive brain disease, perhaps most commonly Rasmussen's chronic encephalitis ${ }^{1}$ but in some cases no clear etiology is established. We present a case of persistent and continuous focal motor seizures, which fulfilled the criteria for epilepsia partialis continua. The evolution of multiple anatomic and functional imaging studies are discussed in light of intra-operative and pathological findings.

\section{CASE REPORT}

A previously healthy nine-year-old left-handed girl presented initially to a local hospital with episodes of left facial twitching. Magnetic resonance imaging (MRI) was unremarkable, and she was treated with carbamazepine. Six months later she woke with unremitting twitching involving the left arm and face. She was admitted to a local hospital and required pentobarbital coma to control the events. Magnetic resonance imaging on admission and one week later were normal. She continued to have seizures after several attempts to wean from pentobarbital coma. On hospital day 14 she was transferred to this

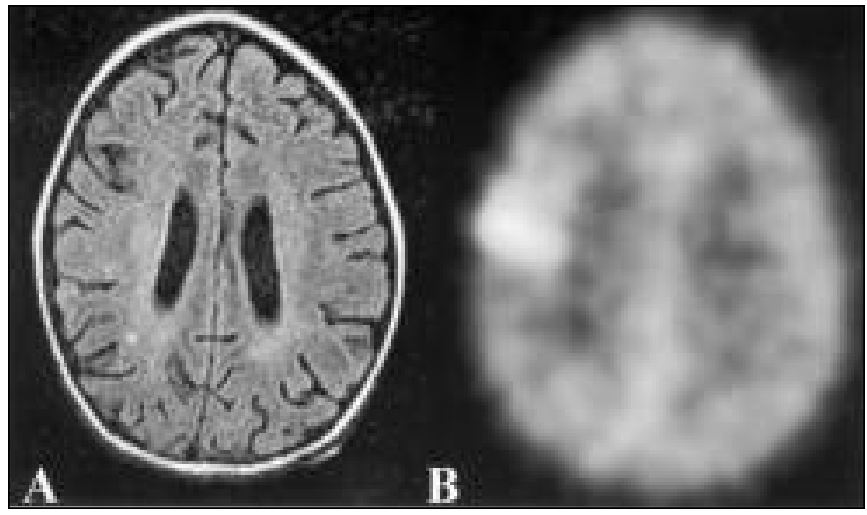

Figure 3: Composite figure of imaging on day 28 of status epilepticus, one week after pentobarbital coma was initiated, two days before surgery. Axial FLAIR image showing improved signal change in right frontotemporal areas with only minimal subcortical hyperintensity remaining (2A). A ${ }^{18} F D G$-PET from the same day scan showing improvement in abnormal uptake of radio-labeled glucose in right frontotemporal regions, now highly localized to motor cortex. 

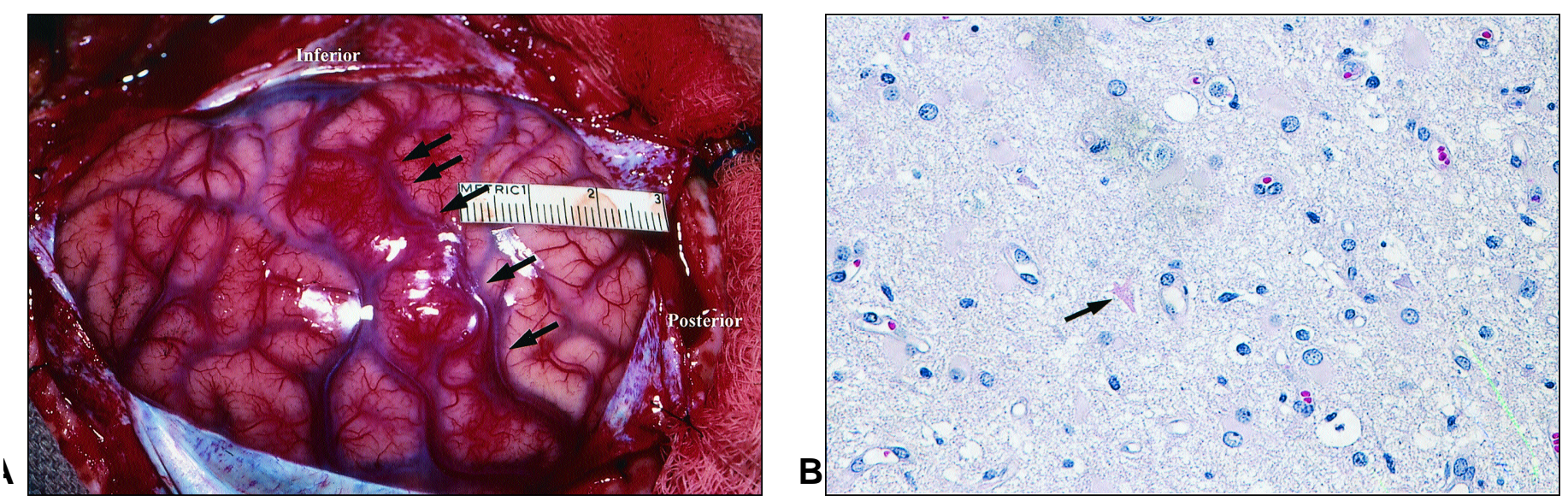

Figure 4: A: Intra-operative photograph showing right motor strip exposed beneath the dura. Arrows delineate hyperemia along the motor strip. B: Pathological specimen of resected cortex. The slide shows thickened vessels, eosinophilic atrophied neurons (arrow) and astrocytes with swollen pink cytoplasm on hematoxylin eosin staining. Only rare lymphocytes and microglia are noted. There is no perivascular cuffing nor spongiform change to suggest Rasmussen's encephalitis (Magnification 20x).

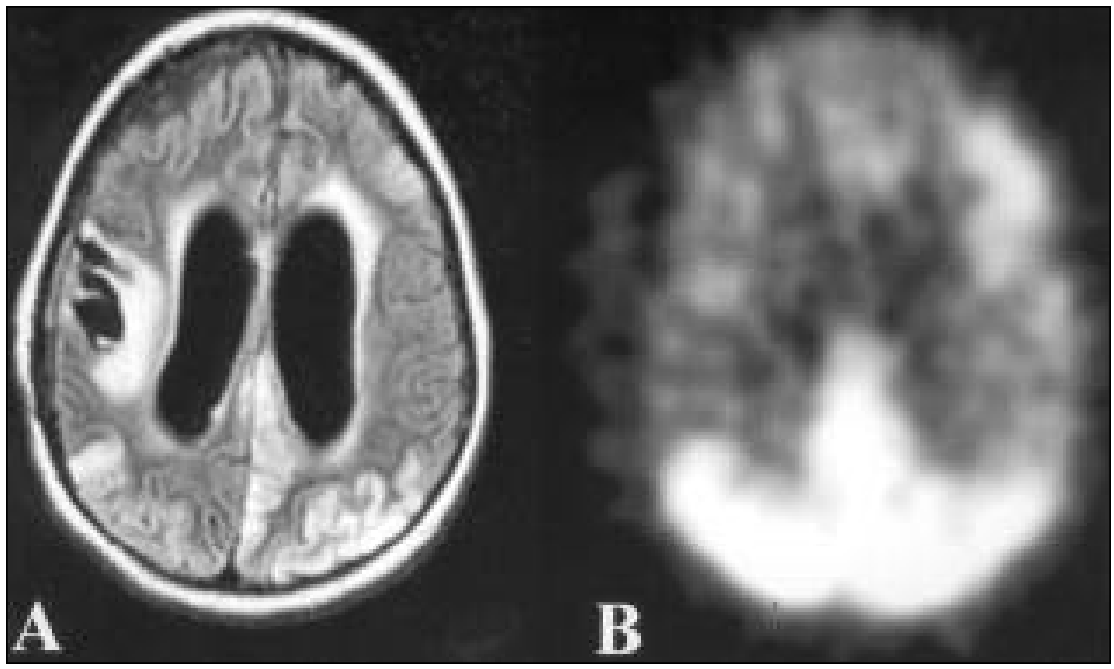

Figure 5: Composite imaging postoperatively and after resumption of seizure activity. Axial FLAIR image two months after the operation showing significant atrophy and widespread bilateral increased cortical and subcortical signal intensity $(\mathbf{5 A})$. An ${ }^{18} \mathrm{FDG}$-PET scan from two weeks after operation showed widespread increases in radio-labeled tracer in bilateral occipital and frontotemporal regions $(\mathbf{5 B})$.

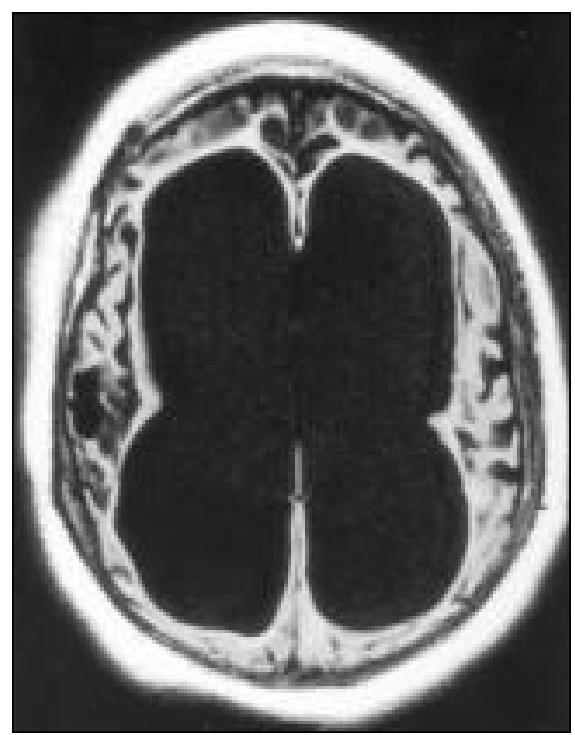

Figure 6: $T 1$ axial fast spin echo image of brain three years postoperatively, showing massive ex vacuo ventricular dilatation with generalized white and gray matter loss. was normal. After a week in a pentobarbital coma, repeat MRI demonstrated improvement of the T2 changes which were now almost resolved apart from mild subcortical hyperintensity (Figure 3A). There was a similar normalization of glucose uptake seen on an ${ }^{18}$ FDG-PET done the same day (Figure 3B). However, with every attempted wean from the drug-induced coma the seizures returned.

Based on persistent focal epileptic discharge, poor response to medical treatment, and lack of a specific diagnosis a right frontotemporal craniotomy with biopsy was undertaken. Once the dura was opened, the inferior portion of the motor strip displayed obvious hyperemia and arterialization of veins indicating massive local shunting of blood (Figure 4A). The inferior 4-cm hyperemic area of precentral gyrus was resected using bipolar cautery and suction. Multiple subpial transections were then performed in the superior portion of the motor strip. These resulted in cessation of clinical seizure activity in her left face, hand and arm. Examination of resected cortex showed extensive neuronal death, cortical gliosis and some reactive astrocytosis in the subcortical white matter, but no specific pathological diagnosis was apparent. The general cortical architecture was preserved and the myelin pattern of the cortex and underlying white matter is normal. Specifically there was no perivascular cuffing, microglial nodules nor spongiform change to suggest Rasmussen's encephalitis nor any extensive evidence of inflammation (Figure 4B).

Seizures recurred 12 hours postoperatively, and over several days events began to manifest clinical and EEG signs of left hemispheric involvement as well as continuation of the previously described right hemisphere abnormalities. An MRI study, performed six days later showed postoperative change with ongoing $\mathrm{T} 2$ prolongation, now also 
appearing to a lesser degree in the left hemisphere at a time when ongoing seizure activity appeared to involve the right side of the body. The patient was placed in a pentobarbital coma again. A follow-up study done two months later showed the progressive nature of the process with generalized cerebral atrophy and multifocal areas of $\mathrm{T} 2$ prolongation consistent with independent focal seizures from both hemispheres (Figure 5A). The new focus of activity on the left was confirmed by left hemisphere abnormalities on concurrent ${ }^{18} \mathrm{FDG}$-PET examination (Figure 5B). Over the next six weeks several attempts to wean from drug-induced coma were made but the seizures invariably returned. Eventually on a combination of primidone, valproate and gabapentin, she was weaned off pentobarbital for the last time. She continued to remain refractory to medical treatment and was finally discharged to long-term care in a persistent vegetative state with intermittent independent seizure activity affecting both sides of her body, which continues to this day. A final imaging study, done three years after presentation, demonstrates near complete loss of cortical volume with massive compensatory dilatation of the ventricular system (Figure 6).

\section{Discussion}

This case documents the evolution of imaging findings during a catastrophic course of persistent and intractable focal SE. We demonstrate a clear correlation between the clinical, neurophysiological, intra-operative, and functional and anatomic imaging findings. Key findings include the correlation of functional imaging abnormalities with disease activity and anatomic changes, the striking increase in local bloodflow, and the lack of a primary pathological diagnosis. These findings suggest that some cases of focal SE are idiopathic, in the original sense of the word, "disease of the self". While animal studies of the effects of prolonged status are well-described, the effects on the human brain of such a catastrophic course are not wellunderstood..$^{1,3}$

In the last 20 years, nuclear imaging studies such as SPECT and PET using both ${ }^{18}$ fluro-2-deoxy-glucose and ${ }^{15}$ oxygen have been used to noninvasively localize seizure foci through the analysis of ictal bloodflow and interictal metabolism (see Spencer for review ${ }^{4}$ ). Despite these studies, little is understood about the dynamics of flow in the microcirculation. Some evidence from animal studies suggests that there is uncoupling of metabolism and blood flow in focal seizures with the requirements of metabolism often outstripping the delivery of oxygenated blood. ${ }^{5}$ On the other hand evidence from human studies suggests that in fact perfusion outstrips metabolic demand. ${ }^{6}$ In 1933, Penfield ${ }^{7}$ described evidence of increased local blood flow in the ictal zone during and after seizure activity:

After the attack the cerebral arteries pulsate violently ...

Their color becomes a bright red and arteries which were not seen to pulsate before the seizure may now begin to do so visibly. In fact this recovery may go so far that the veins themselves take on an arterial hue. ${ }^{7}$

This dramatic 70-year-old description is uncannily similar to the gross operative findings in this case.

Advances in structural imaging have further supplemented functional localization in SE. Neuroimaging of the brain directly after prolonged epileptic seizures, either focal or generalized, may reveal focal cerebral abnormalities that are typically transient. Cerebral hypodensities that enhance with contrast on computed tomography (CT) have been reported since $1980 .^{8}$ In most cases the changes suggested the development of focal cerebral cytotoxic edema. By the early 1990s, reports of T2 hyperintensity changes in focal areas associated with SE on MRI began appearing in the literature. ${ }^{8-18} \mathrm{~A}$ variety of metabolic events which lead to edema have been invoked to explain the changes including cytotoxic edema due to swelling of glial cells, increases in intracellular sodium concentration secondary to $\mathrm{Na} / \mathrm{K}$ pump failure ${ }^{19}$ and vasogenic edema caused by excessive glutamate release. ${ }^{12}$

There are several imaging features in this case that merit discussion. Firstly the initial imaging study, obtained six months prior to the onset of status was normal, as was an MRI obtained a week after onset of SE. Widespread regional T2 changes first appeared a full two weeks after SE began and were concordant with both EEG and metabolic abnormalities on ${ }^{18}$ FDG-PET. By contrast, perfusion at the microvascular level as assessed by ${ }^{99}$ TC-HMPAO-SPECT remained normal. We hypothesize that the increased blood flow visualized by MRA was due to increased arterio-venous shunting as visualized intraoperatively. Magnetic resonance angiogram changes of this nature have been reported in only one patient previously. ${ }^{12}$ The attenuation of the T2 and the metabolic abnormalities during pentobarbital coma has not been reported previously nor has concordance of these T2 changes with visualized arterialization of surface veins and hyperemia in the same area at craniotomy. Unlike previous reports in which the $\mathrm{T} 2$ changes tended to resolve, favoring the cytotoxic edema hypothesis, the changes in this case persisted for months after the onset of status presumably reflecting the development of dense gliosis and neuronal death as demonstrated neuropathologically. Together, our findings suggest that cerebrovascular responses to SE in this patient, which appeared to be largely microvascular, were insufficient to adequately supply local neuronal demand, contributing to cell death.

Perhaps the most dramatic structural finding in this case was the relentless progressive generalized brain atrophy over the course of the illness. The literature in this area includes detailed descriptions of progressive focal atrophy on serial MRIs after SE in mesial structures. ${ }^{14,20}$ Similarly in more intractable disease such as epilepsia partialis continua secondary to Rasmussen's encephalitis, atrophy is extensive but appears limited to the affected hemisphere. ${ }^{21}$ The explanation for the widespread atrophy in our patient is not clear. The role of three weeks of intravenous dexamethasone in generalized brain atrophy in this case must be considered, but the degree of atrophy in combination with previous experience with steroid treatment in other disease states suggests that additional factors must have contributed to the development of widespread atrophy. At present we cannot differentiate between the roles of numerous biochemical consequences of repeated seizures such as ionic fluxes, kinase activation, early and late gene expression, protein expression and modification, synaptic reorganization, the roles of indirect consequences of seizures such as local hypoxia, hypotension, and acidosis (see $\mathrm{Cole}^{3}$ for review).

Catastrophic epilepsy arising in childhood may be due to structural, infectious or metabolic disturbances. Structural abnormalities include cortical dysgenesis, congenital 
demyelinating disease, and vascular insults such as venous occlusion, anoxic injury and major trauma. Infectious etiologies include viral encephalitis, focal or multifocal cerebritis, and perhaps chronic encephalitis (Rasmussen's disease), although no causative agent has been identified, and recent studies have suggested a potential autoimmune basis for the latter. Metabolic disorders as a cause of catastrophic seizures are generally described in terms of seizure types such as childhood encephalopathy with myoclonus and myoclonic-astatic seizures (see Shields ${ }^{22}$ for discussion). Recently there have been a number of case reports of rare metabolic disorders engendering severe intractable seizures, including Alpers syndrome, ${ }^{23,24}$ selenium deficiency, ${ }^{25}$ peroxisomal disease, ${ }^{26}$ gluthathione synthetase deficiency, ${ }^{27}$ glucose transporter deficiency syndrome and sulphite oxidase deficiency. ${ }^{28}$ Most of these were identified in association with infantile seizures soon after birth rather than in later childhood. These protean conditions demonstrate that while there is no single etiology for, nor common pathological abnormality in catastrophic epilepsy arising in childhood, all of these conditions are associated with a poor neurological outcome. The presence of epilepsia partialis continua appears to confer a particularly poor prognosis regardless of the cause. ${ }^{29}$

Large case series of catastrophic childhood epilepsy are rare. The natural history of Rasmussen's encephalitis has been recently documented in a longitudinal study of 16 patients demonstrating typical neuroradiographic features and also a subgroup of slightly older patients who may have a slight better prognosis. ${ }^{30}$ In a study of 15 children without Rasmussen's encephalitis, although it was possible to classify the patients with respect to seizure localization, either multi-focal or lateralized, the outcome in all cases was poor. ${ }^{24}$ Of the 15 cases, only eight had a unifying diagnosis. Three had the Alpers syndrome, three were thought to have cerebral dysgenesis, one had anoxic damage, one had congenital cytomegalovirus, and seven patients had no specific diagnosis. Other efforts at defining the syndrome of catastrophic epilepsy by seizure phenomenology have been equally unrevealing. Coppola ${ }^{31}$ described an epileptic condition in a number of patients characterized by intractable focal seizures and poor intellectual outcomes. Inclusion in the group required an unidentified cause, but the coining of term "malignant developmental arrest" may have been the most useful contribution. In those that do have a common identifiable cause such as acquired cortical damage, knowledge of the etiology appears to have little impact on the course of the disease. In a retrospective review of catastrophic epilepsy in 42 patients with a history of encephalitis, only a small subset of those with seizures localized by EEG to one temporal lobe appeared to have a favourable prognosis. ${ }^{32}$

Recent guidelines for evaluating patients with catastrophic epilepsy have concentrated on imaging in an effort to identify localized abnormalities such as cerebral dysgenesis so that either focal cortical resection or hemispherectomy may be added to the treatment options. This approach is based on follow-up studies of small numbers of surgical patients with catastrophic seizures who have had sustained periods of seizure freedom and even demonstrated a tendency to "catch-up" developmentally if operated on early enough. ${ }^{33}$

In our case the etiology remains obscure. The biochemical and metabolic evaluation was negative. The neuropathological examination of the biopsy specimen did not reveal a specific diagnosis, although it was taken from the center of the most consistently involved cortical region and included surrounding tissue and subcortical white matter. Detailed examination revealed only evidence of cell death and gliosis, with no indication of cerebral dysgenesis, inflammatory changes, viral inclusions or tumor. While it is possible that subtle dysgenesis could have been missed, especially after considerable neuronal loss had occurred, no evidence of a structural abnormality was apparent on MRI prior to the development of seizure-related structural changes. We suggest that SE in this patient was indeed idiopathic in the strict sense of the word, that is a consequence of some unique constellation of activity, connectivity, and stimulation in this individual's brain that resulted in destabilization of the normal neuronal network architecture. This view, which is conjectural, is proposed as a hypothesis that might be tested using techniques of computational modeling.

This detailed case study of the catastrophic course of epilepsia partialis continua in a child reveals several intriguing associations. The employment of structural and functional imaging illustrates the tight correlation of abnormal electrical, metabolic activity and the visualized cortical blood flow. Furthermore, the development of local and generalized structural and metabolic changes were only transiently affected by a range of therapies demonstrating the relentless progressive nature of the damage caused by such constant activity.

\section{ACKNOWLEDGEMENTS}

We thank the patient and her family for their cooperation and the medical and surgical staff at Massachusetts General Hospital for their care over the course of the patient's illness.

\section{REFERENCES}

1. Wasterlain C, Fujikawa D, Penix L, Sankar R. Pathophysiological mechanisms of brain damage from status epilepticus. Epilepsia 1993; 34: S37-S53.

2. Molyneux P, Barker R, Thom M, et al. Successful treatment of intractable epilepsia partialis continua with multiple subpial transsections. JNNP1998; 65: 137-138.

3. Cole A. Is epilepsy a progressive disease? The neurobiological consequences of epilepsy. Epilepsia 2002; 41(Suppl 2): S13-S22.

4. Spencer S, Bautista E. Functional neuroimaging in localization of the ictal onset zone. In: Henry T, Duncan J (Eds.) Functional Imaging in the Epilepsies, Philadelphia: Lippincott Williams and Wilkins, 2000: 285-296.

5. Bruehl C, Hagemann G, Witte O. Uncoupling of blood flow and metabolism in focal epilepsy. Epilepsia 1998; 39: 1235-1242.

6. Franck G, Sadzot B, Salmon E, et al. Regional cerebral bloodflow and metabolic rates in human focal epilepsy and status epilepticus. Adv Neurol 1986; 44 : 935-948.

7. Penfield W. The evidence of a cerebral vascular mechanism in epilepsy. Ann Intern Med 1933; 7: 303-310.

8. Henry T, Drury I, Brunberg J, et al. Focal cerebral magnetic resonance changes associated with partial status epilepticus. Epilespia 1994; 35: 35-41.

9. Callahan D, Noetzel M. Prolonged absence status epilepticus associated with carbamazepine therapy, increased intracranial pressure and transient MRI abnormalities. Neurology 1992; 42: 2198-2201.

10. Fazekas F, Kapeller P, Schmidt R, et al. Magnetic resonance imaging and spectroscopy findings after focal status epilepticus. Epilepsia 1995; 36: 946-949.

11. Kramer R, Luders H, Lesser R, et al. Transient focal abnormalities 
of neuroimaging studies during focal status epilepticus. Epilepsia 1987; 28: 528-532.

12. Lansberg M, O'Brien M, Norbash A, et al. MRI abnormalities associated with partial status epilepticus. Neurology 1999; 52:1021-1027.

13. Lazeyras F, Blanke O, Zimine I, et al. MRI, 1H-MRS, and functional MRI during and after prolonged non-convulsive seizure activity. Neurology 1999; 55: 1677-1682.

14. Meierkord H, Wieshmann U, Niehaus L, Lehmann R. Structural consequences of status epilepticus demonstrated with serial magnetic resonance imaging. Acta Neurologica Scadinavica 1997; 96: 127-132.

15. Najm I, Wang Y, Shedid D, et al. MRS metabolic markers of seizures and seizure-induced neuronal damage. Epilepsia 1998; 39: 244-250.

16. Riela A, Sires B, Penry J. Transient magnetic resonance imaging abnormalities during partial status epilepticus. J Child Neurol 1991; 6:143-145.

17. Wieshmann U, Woermann F, Lemieux L, et al. Development of hippocampal atrophy: a serial magnetic resonance imaging study in a patient who developed epilepsy after generalized status epilepticus. Epilepsia 1997; 38: 1238-1241.

18. Yaffe K, Ferriero D, Barkovich J, Rowley H. Reversible MRI abnormalities following seizures. Neurology 1995; 45: 104-108.

19. Zhong J, Petroff O, Prichard J. Barbiturate-reversible reduction of water diffusion coefficient in flurothyl-induced status epilepticus in rats. Magn Reson Med 1995; 33: 253-256.

20. Nohria V, Lee N, Tien R, et al. Magnetic resonance imaging evidence of hippocampal sclerosis in progression: a case report. Epilepsia 1994; 35: 1332-1336.

21. Bien C, Urbach H, Deckert M, et al. Diagnosis and staging of Rasmussen's encephalitis by serial and histopathology. Neurology 2002; 58: 250-257.
22. Shields WD. Catastrophic epilepsy in childhood. Epilepsia 2000; 41(Suppl 2):S2-S6.

23. Gauthier-Villars M, Landrieu P, Cromier-Daire V, et al. Respiratory chain deficiency in Alpers syndrome. Neuropediatrics 2001; 32:150-152.

24. Ishii K, Oguni H, Hayashi K, et al. Clinical study of catastrophic infantile epilepsy with focal seizures. Pediatr Neurol 2002; 27: 369-377.

25. Ramaekers VT, Calomme M, Vanden Berghe D, Makropoulos W. Selenium deficiency triggering intractable seizures. Neuropediatrics 1994; 25:217-223.

26. Takahashi Y, Suzuki Y, Kumazakai K, et al. Epilepsy in peroxisomal diseases. Epilepsia 1997; 38:182-188.

27. Ristoff E, Mayatepek E, Larsson A. Long-term clinical outcome in patients with glutathione synthetase deficiency. J Pediatr 2001; 139:79-84.

28. Slot HM, Overweg-Plandsoen W, Bakker HD, et al. Molybdenumcofactor deficiency: an easily missed cause of neonatal convulsions. Neuropediatrics 1993; 24:139-142.

29. Baram TZ, Mitchell WG, Snead OC. Prognostic significance of acute epilepsia partialis continua. Pediatr Neurol 1991; 7(2): 144146.

30. Bien CG, Widman G, Urbach $\mathrm{H}$, et al. The natural history of Rasmussen's encephalitis. Brain 2002; 125(8): 1751-1759.

31. Coppola G, Plouin P, Chiron C, Robain O, Dulac O. Migrating partial seizures in infancy: a malignant disorder with developmental arrest. Epilepsia 1995; 36:1017-1024.

32. Trinka E, Dubeau F, Andermann F, et al. Clinical findings, imaging characteristics and outcome in catastrophic post-encephalitic epilepsy. Epileptic Disord 2000; 2(3):153-162.

33. Wyllie E. Surgery for catastrophic localization-related epilepsy in infancy. Epilepsia 1996; 37(Suppl 1): S22-S25. 